\title{
MODEL TATA KELOLA KOMPUTASI HIJAU BERBASIS DOKUMEN UNTUK UNIVERSITAS BINA NUSANTARA
}

\author{
Nuril Kusumawardhani Soeprapto Putri; Argogalih; Hudiarto \\ Information Systems Department, School of Information Systems, Binus University \\ Jl. K.H. Syahdan No. 9, Palmerah, Jakarta Barat 11480 \\ missty81@gmail.com; argo.galih@yahoo.com; hudiarto@binus.edu
}

\begin{abstract}
The lack of green computing governance model for environment of universities in Indonesia becomes one major factor to conduct this research. In fact, the teaching and learning activities in campuses depend on support of information system and information technology. Various studies on green computing were observed. However, the suitable model for green computing in the area of private university Indonesia has not been observed yet. Referring to Green ICT Framework by University of Michigan and Connection Research as well as green computing framework by Adcuent, the green computing model for private university in Indonesia was developed through this research. Although the research object was observed in Bina Nusantara University, Jakarta, Indonesia, it is adoptable for other private universities to evaluate their information system and information technology performance surround campuses. Green computing governance is part of information system and information technology strategic plan. Therefore, the management of university should fully concern towards this matter.
\end{abstract}

Keywords: model, green computing governance, environment, campus

\begin{abstract}
ABSTRAK
Belum adanya model tata kelola komputasi hijau bagi lingkungan kampus di Indonesia menjadi faktor utama dilakukannya penelitian ini. Padahal, kegiatan kampus yang padat dengan proses belajar mengajar tidak terlepas dari dukungan sistem dan teknologi informasi, bahkan tidak bisa dipungkiri bahwa sistem dan teknologi informasi tersebut menjadi telah tulang punggungnya. Berbagai studi literatur mengenai topik komputasi hijau sudah banyak ditemukan. Namun model yang sesuai untuk diimplementasikan bagi perguruan tinggi swasta di Indonesia belum ditemukan. Mengacu pada Green ICT Framework yang dibuat oleh Universitas Michigan dan Connection Research serta metodologi komputasi hijau milik Adcuent, peneliti mengembangkan model tersebut menjadi sebuah model komputasi hijau. Walaupun obyek penelitian dilakukan di Universitas Bina Nusantara, Jakarta, Indonesia, model ini dapat diadopsi oleh perguruan tinggi swasta lainnya untuk mengevaluasi kinerja Sistem Informasi dan teknologi informasi di lingkungan kampus di Indonesia. Tata kelola komputasi hijau termasuk dalam perencanaan strategi sehingga sudah selayaknya mendapat perhatian penuh dari pimpinan perguruan tinggi. Dengan demikian penghematan energi, penanganan limbah sistem dan teknologi informasi menjadi terkendali serta ancaman bahaya racun yang bisa mengganggu kesehatan dapat dihindari.
\end{abstract}

Kata kunci: model, tata kelola komputasi hijau, lingkungan, kampus 


\section{PENDAHULUAN}

Pada bulan Oktober 2012, terjadi kejadian yang cukup menghentak masyarakat dunia, khususnya masyarakat Amerika Serikat. Badai Sandy yang menghantam sebagian wilayah di benua Amerika tersebut, membuat lumpuh kota-kota jantung dunia seperti New York. Dikutip dari Utomo (2012), Al Gore, mantan Wakil Presiden Amerika Serikat, adalah salah satu pihak yang dalam refleksinya mengaitkan kontribusi perubahan iklim dalam besarnya dampak badai Sandy. Ia meyakini bahwa badai Sandy tak cuma dipengaruhi faktor cuaca. Hal senada disampaikan oleh Charles Green \& Bruce Monger dari Universitas Cornell, mereka menampilkan bukti bahwa bongkahan es meleleh di benua antartika, sehingga berdampak pada terjadinya pemanasan global, berkontribusi pada pola atmosfer yang mengirimkan "ledakan" dingin ke wilayah Kanada dan Amerika Serikat bagian timur (Barrett, 2012). Kondisi ini disebabkan oleh meningkatnya suhu temperatur bumi yang disebabkan oleh meningkatnya aktifitas dan fasilitas hidup manusia. Munculnya teknologi-teknologi yang semakin canggih, memberikan dampak yang cukup besar pada terjadinya penamasan global. Sheikh \& Lanjewar (2010) menyatakan bahwa "permintaan energi teknologi informasi berkembang 12 kali lebih cepat daripada permintaan energi secara keseluruhan, kemudian Pusat Data menyumbang lebih dari 150 metrik ton CO2 per tahunnya dan volume ini terus-menerus bertambah. Maka dari itu, implementasi dari metode komputasi hijau ini sangatlah penting. Tidak hanya dilihat dari sisi ekonomi, sisi sosial serta kewajiban secara etik juga mendukung dilakukannya penelitian ini.

Kochhar \& Garg (2011) melalui penelitiannya memaparkan beberapa alasan yang melatar belakangi suatu organisasi untuk mengimplementasikan komputasi hijau. Di antaranya adalah perubahan iklim yang telah dibahas pada bagian awal dari kajian ini. Selain itu masalah penghematan yang dapat dilakukan dengan menerapkan metode komputasi hijau. Pengurangan biaya energi dari penggunaan server, cooling dan lainnya merupakan penghematan yang sangat signifikan bagi organisasi pada umumnya. Faktor ketersediaan energi juga menjadi latar belakang dari adanya metode ini. Semakin berkurangnya suplai energi tidak dibarengi dengan peningkatan permintaan energi. Dengan adanya sistem energi yang lebih efisien akan menjamin sistem daya yang lebih sehat. Kehandalan dari perangkat hardware juga meripakan aspek yang sangat penting dalam komputasi hijau. Hal ini dikarenakan dapat mengurangi biaya yang mengarah pada system failures dan $e$-waste.

Dalam konteks pembuatan perencanaan strategi sistem dan teknologi informasi, pentingnya penelitian yang mendalam tentang komputasi hijau menjadi salah satu faktor teknologi eksternal (Gambar 1).

Dalam dunia edukasi, kehidupan dan lingkungan kampus yang nyaman juga didambakan oleh semua orang yang terlibat di dalam kegiatan kampus tersebut. Dampak negatif akibat penggunaan sistem dan teknologi informasi (SI/TI) seharusnya bisa dikurangi bahkan dihindari. Di sisi lain penggunaan SI/TI yang menjadi tulang punggung kegiatan penelitian dan belajar-mengajar justru menimbulkan dampak yang negatif apabila tidak ditangani dengan seksama.

Berdasarkan latar belakang tersebut, penelitian ini bertujuan untuk mendapatkan sebuah model tata kelola komputasi hijau bagi universitas swasta di Indonesia, agar penggunaan energi listrik yang dibutuhkan dalam pengoperasian SI/TI dapat dikurangi dari tahun ke tahun. Hal itu dapat dicapai dengan melakukan pemilihan alat-alat SI/TI yang ramah lingkungan, serta cara pemakaian dan pemeliharaan. Selain itu tata kelola limbah dari peralatan SI/TI tersebut dapat ditangani dengan baik dan meminimumkan efek pencemarannya. Adapun manfaat yang akan diperoleh dari hasil penelitian ini adalah terjadinya penghematan energi di perguruan tinggi, dan dapat digunakan sebagai model untuk instansi pendidikan tinggi lainnya, penanganan limbah SI/TI menjadi terkendali karena terjadinya pemilihan perangkat keras dan piranti lunak yang ramah lingkungan, dan menghindari ancaman bahaya racun yang ditimbulkan dari limbah perangkat keras. 


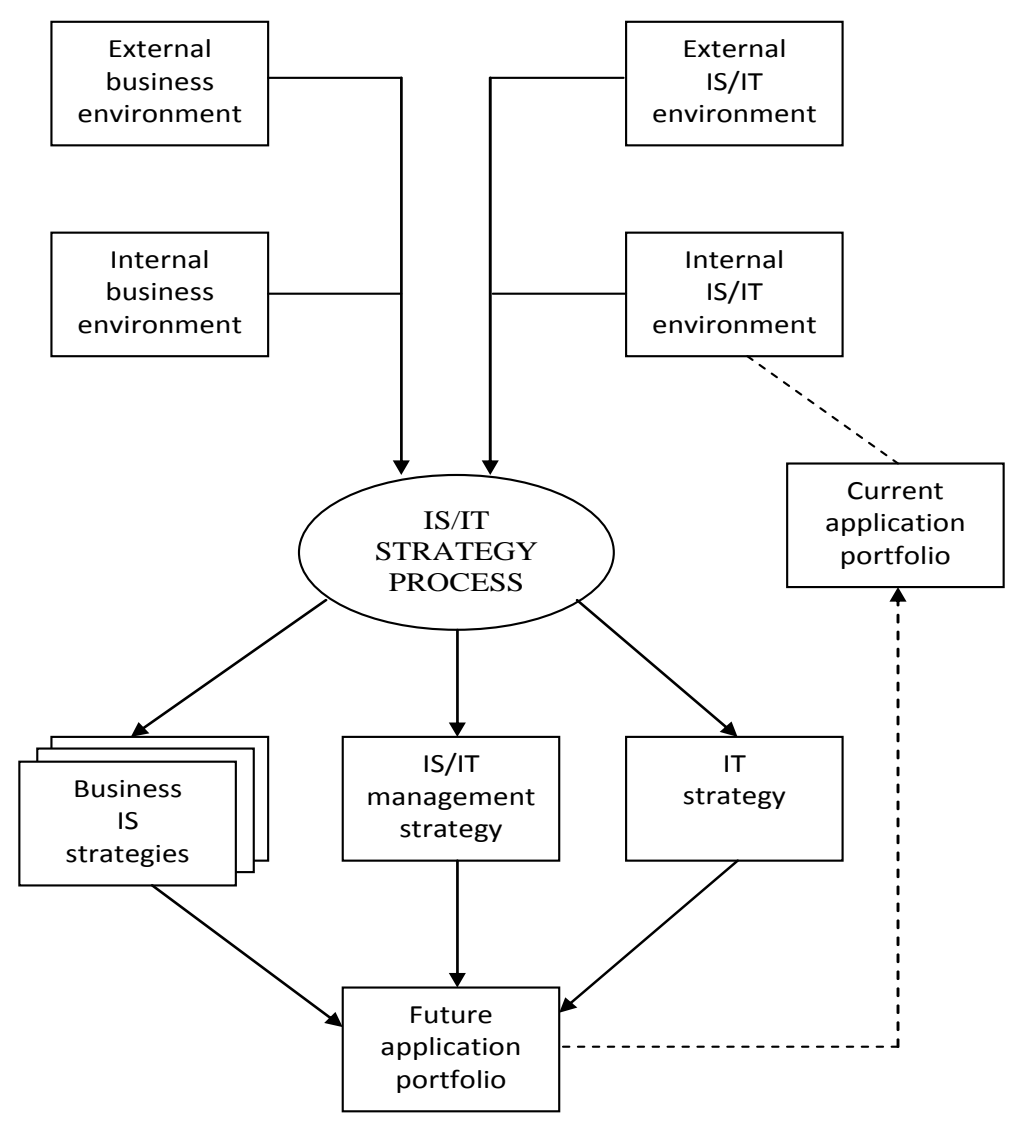

Gambar 1 Model Strategis SI/TI (Ward \& Peppard, 2002)

\section{METODE}

Metodologi penelitian yang digunakan adalah dengan menggunakan berbagai macam studi literatur dari berbagai macam sumber yang terkait dengan komputasi hijau. Selain itu dilakukan wawancara dari pejabat yang berwenang dan observasi secara langsung pada lingkungan SI/TI pada Universitas Bina Nusantara sebagai obyek penelitian ini.

\section{HASIL DAN PEMBAHASAN}

\section{Komputasi Hijau (Green IT atau Green Computing)}

Green atau yang dalam Bahasa Indonesia adalah "ramah lingkungan”, pada umumnya terkait dengan masalah kesehatan dan juga memiliki nilai ekonomis (Prothero\&Fitchett, 2000 dalam Talebi \& Way, 2009). Di lingkungan teknologi informasi sendiri, terminologi ini dikenal dengan istilah green computing atau komputasi hijau. Definisi dari komputasi hijau menurut Lamb (2009, p1) adalah penggunaan teknologi informasi secara efektif untuk mencapai pengurangan dalam konsumsi energi, dengan mengakuisisi suatu solusi penghematan energi secara efisien. Pendapat lain dari Tomlinson (2010, p13) yaitu penghijauan melalui IT (Greening through IT) menyajikan perluasan pemahaman manusia, terhadap bagaimana suatu teknologi komputer dapat menempatkan peradaban manusia untuk bertanggung jawab pada permasalahan lingkungan, serta memungkinkan suatu individu dan kelompok 
untuk menyelesaikannya. Harris (2008, p31) memaparkan teori komputasi hijau sebagai arahan yang mengacu pada suatu langkah yang terbaik, dalam penggunaan sumber daya komputer secara efisien. Lebih penting lagi bahwa, Komputasi hijau bukanlah mengacu pada rancangan "biodegradable" dari suatu produk, melainkan tentang penggunaan komputer dan sumber daya secara efisien terutama pada peralatan teknologi yang tidak bisa didaur ulang (Chakraborty, Bhattacharyyal, \& Nargiza, 2009).

Dari berbagai definisi di atas, dapat ditarik kesimpulan bahwa komputasi hijau merupakan suatu metode yang dapat digunakan oleh para pengguna teknologi informasi, agar dapat mencapai penghematan energi secara efektif dan efisien melalui berbagai macam metode tertentu.

\section{Metode Komputasi Hijau}

Lamb (2009, p206-209) memaparkan enam langkah yang dapat diaplikasikan oleh suatu perusahaan dan organisasi yang ingin mencapai komputasi hijau. Langkah pertama adalah mengkomunikasikan perencanaan komputasi hijau dan memilih ketua pelaksanaan (energy czar). Langkah berikutnya adalah melakukan konsolidasi dan virtualisasi. Konsolidasi pada kegiatan operasional teknologi informasi dan menggunakan virtualisasi untuk mengurangi server footprints serta penggunaan energi, merupakan langkah yang paling dikenal dan strategi yang paling sering diimplementasikan dalam beberapa tahun belakangan ini. Kemudian melakukan pemasangan unit-unit pendingin (cooling units) yang hemat energi. Infrastruktur daya dan pendingin (power and cooling) yang mendukung perangkat teknologi informasi di dalam suatu data center yang menggunakan energi secara signifikan, yaitu sekitar 50 persen dari total penggunaan (Laporan EPA pada Kongres Efisiensi Energi Server dan Data center, 2007 di Lamb, 2009, p129). Langkah keempat adalah melakukan pengukuran dan pengoptimalan. Dilanjutkan dengan pengimplementasian aplikasi yang efisien dan deduplikasi data. Deduplikasi data merupakan suatu metode yang digunakan untuk mengurangi kebutuhan akan tempat penyimpanan (storage) dengan cara mengurangi data redudansi. Langkah terakhir adalah memanfaatkan sistem rebate dan insentif. Dalam hal ini, perusahaan dapat memanfaatkan sistem potongan harga (rebate) dan insentif untuk memperbarui perangkat teknologi informasi yang hemat energi dan mengadopsi kegiatan operasional yang efektif.

Selain kedua metode di atas, Adcuent (2010) mengembangkan suatu metodologi komputasi hijau yang terdapat pada Gambar 2 dan telah digunakan oleh berbagai proyek komputasi hijau di seluruh dunia. Pada Gambar 2 terlihat dalam metodologi ini, perusahaan perlu untuk mengembangkan suatu perencanaan komputasi hijau yang berkelanjutan dengan tahapan-tahapan sebagai berikut: daur ulang, proses pengambilan keputusan untuk membeli perangkat ramah lingkungan, melakukan tinjauan terhadap penggunaan kertas, dan pelestarian energi.

\section{Beberapa Penerapan Green IT Best Practice}

\section{University of Michigan}

Penerapan best practice komputasi hijau di lingkungan Universitas Michigan, diawali dengan didirikannya climate savers computing initiative (CSCI) yang digagas oleh Larry Page, pendiri Google serta alumnus dari universitas tersebut. CSCI merupakan organisasi nirlaba dari para pengguna yang sadar akan lingkungan, bisnis dan konservasi, dengan tujuan untuk meningkatkan keefisienan komputasi serta penerapan power management tools. Universitas Michigan mencanangkan program climate savers computing initiative @U-M (CSCI @ U-M) untuk menanggulangi permasalahan lingkungan TI, seperti individual computing practice dan data/server impact di dalam kampus (University of Michigan, 2012). 


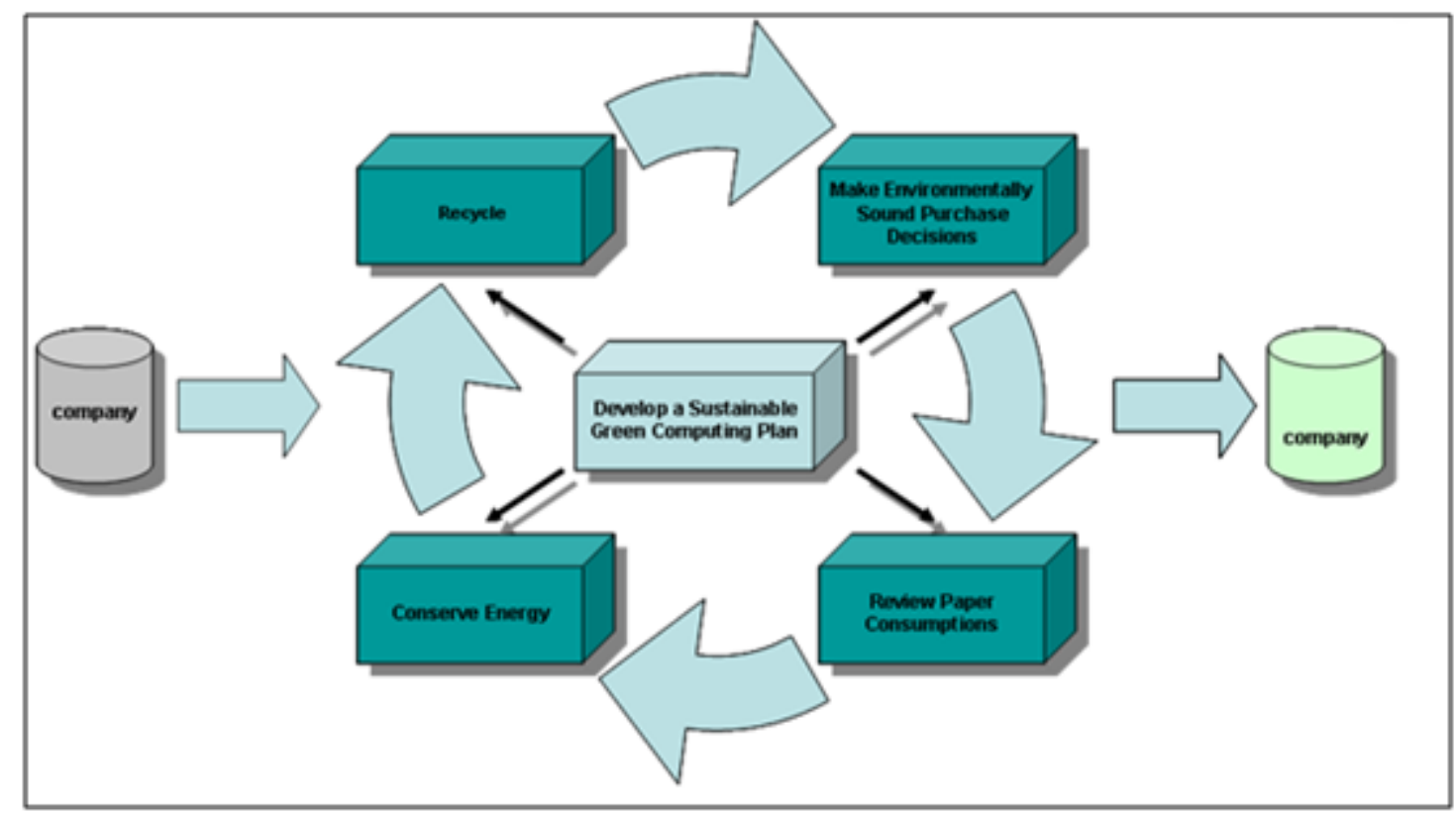

Gambar 2 Metodologi komputasi hijau (Adcuent, 2010)

Langkah-langkah yang oleh Universitas Michigan dalam penerapan green IT best practice adalah sebagai berikut (Stuenkel, 2009). Dibentuknya dua tim sukarelawan, yaitu tim teknologi desktop (Desktop Technology team) dan tim Pusat Data/Server ( Data center/Server Room team). Tim teknologi desktop, bertanggung jawab pada pengembangan praktik komputasi penghematan energi bagi mahasiswa, fakultas dan staf. Sedangkan tim Pusat Data/Server, bertanggung jawab untuk menetapkan best practice bagi green IT computing center dan ruang server, serta memberikan tindakan rekomendasi yang dapat dilakukan untuk mengurangi penggunaan energi dengan fasilitas tersebut. Kemudian dilanjutkan dengan meningkatkan kesadaran pada komunitas kampus melalui website, newsletter dalam bentuk surat elektronik (email), membuat rangkaian poster yang berisikan sub bagian dari best practice. Hal ini diharapkan dapat memupuk kesadaran dan perilaku para pengguna di lingkungan Universitas Michigan. Langkah berikutnya adalah melakukan evaluasi dalam memutuskan suatu pembelian (purchasing). Misalnya dalam pembelian CPU serta monitor, keefisienan dalam penggunaan energi menjadi faktor utama pada saat pembelian. Universitas Michigan berpatokan pada standar Energy Star. Energy Star merupakan gerakan komputasi hijau yang diluncurkan pada tahun 1992. Energy Star merupakan label yang diberikan pada peralatan ICT yang telah berhasil meminimalkan penggunaan energi (Kochhar \& Garg, 2011). Penerapan Computer Power dan Patch Management (CPPM) pada setiap bagian atau unit kampus termasuk kedalam best practice ini. CPPM berperan dalam penekanan pengaturan daya pada setiap komputer dan mengamati perilaku penggunanya. Selanjutnya, penggunaan Thin Client pada pelaksanaan CSCI @ U-M dan yang tidak kalah pentingnya adalah pengelolaam E-Waste. Universitas Michigan menggunakan metode 3(tiga) R dalam pengelolaan E-Waste, yaitu Reduce, Reuse dan Recycle. Peralatan elektronik yang sudah tidak mampu untuk memenuhi peranan aslinya, dialihfungsikan kepada peranan yang lain. Misalnya, sebuah komputer yang tadinya berfungsi sebagai komputer kantor, kemudian digantikan dengan yang lebih cepat dengan kapasitas yang lebih banyak, dapat dijadikan sebagai mesin kiosk. Sangatlah tidak bijaksana jika peralatan itu dibuang begitu saja, dikarenakan kandungan berbahaya yang ada pada material komputer tersebut. Langkah yang terakhir adalah penghematan energi dengan konsolidasi dan virtualisasi.

Hasil yang dicapai di awal penerapannya adalah Universitas Michigan berhasil menghemat sebesar 1 juta kilowatt jam/tahun pada penggunaan energi listrik. Hal ini setara dengan penghematan 
biaya sebesar $\$ 90.000$ per tahunnya. Dengan diterapkannya CPPM pada 12.000 workstation, Universitas Michigan mengharapkan dapat menghemat dua juta kilowatt jam per tahunnya atau setara dengan $\$ 180,000$ per tahun.

\section{Kerangka Kerja Green ICT Connection Research-RMIT University}

Universitas RMIT bekerja sama dengan Connection Research mengembangkan sebuah kerangka kerja komputasi hijau yang dinamakan The Connection Research-RMIT Green ICT Framework. Kerangka kerja ini terdiri dari empat komponen vertikal atau disebut dengan "pilar", di mana setiap komponen tersebut dibagi menjadi beberapa area spesifik dari Green ICT serta 5 (lima) komponen horisontal, atau dikenal dengan “tindakan (action)” (Gambar 3).

Komponen vertikal yang pertama adalah siklus hidup peralatan (equipment lifecycle). Pilar ini mencakup akuisisi dan pembelian dari peralatan ICT serta pembuangan (disposal) atau daur ulangnya di akhir siklus hidup peralatan tersebut. Pada tahapan akuisisi dan pembelian, tingkat efisiensi energi, emisi siklus hidup produk dan level dari limbah menjadi faktor-faktor yang menentukan dalam pembelian suatu peralatan ICT. Untuk mengurangi limbah, suatu organisasi dapat membeli peralatan ICT dari pemasok yang mengirimkan barangnya, kemudian membuka kemasan serta membawa kemasan tersebut sehingga bisa digunakan kembali. Dalam tahapan pembuangan (disposal), peralatan ICT yang sudah tidak digunakan dapat dibuang atau dihancurkan, namun dapat juga dijual atau diberikan kepada individu atau organisasi lain.

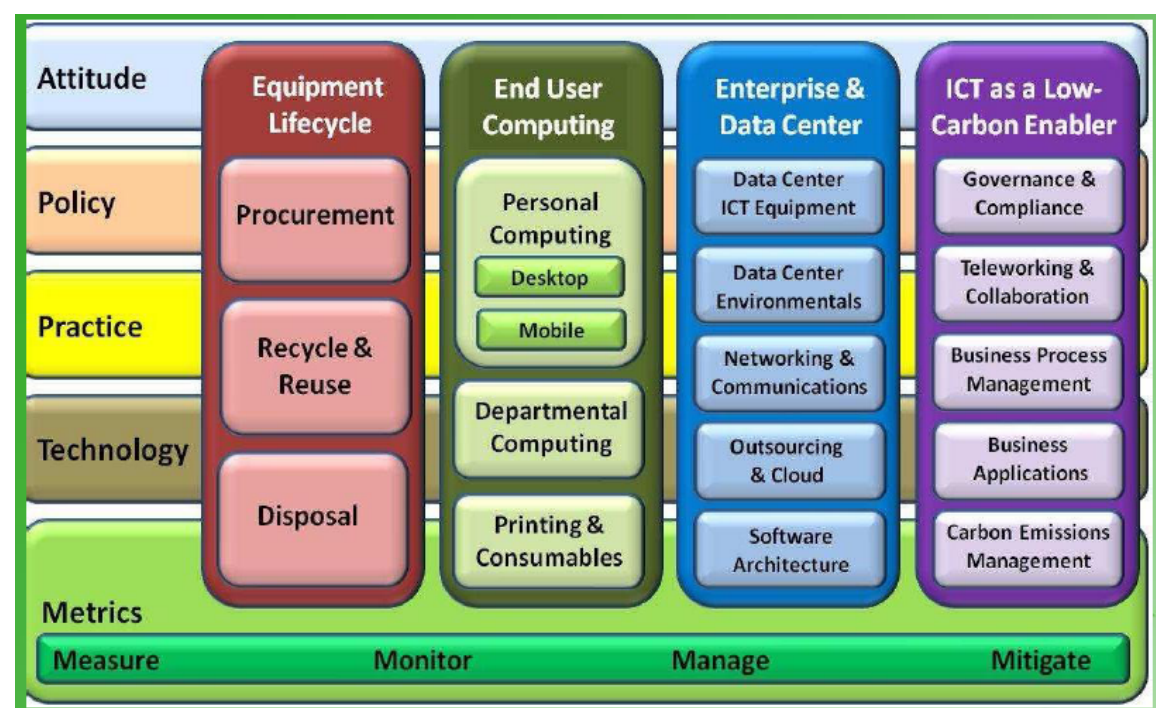

Gambar 3 The Connection Research-RMIT Green ICT Framework (Connection Research, 2010)

Komponen vertikal yang berukutnya adalah end user computing. End user computing merupakan bagian dari proses ICT yang dikendalikan oleh para pengguna (end user). Terdapat empat area, yaitu personal computing (desktop), personal computing (mobile), departmental computing dan printing \& consumables. Pada personal computing (desktop), dirinci lagi menjadi dua bagian, yaitu desktop computing dan mobile computing. Dalam konteks desktop, tindakan penting yang dapat dilakukan di antaranya adalah mematikan $P C$ jika tidak digunakan, penggunaan teknik pengelolaan daya PC dan teknologi penting lainnya seperti thin client computing. Mobile computing dijadikan sebagai salah satu bagian dari personal computing mengingat meningkatnya jumlah pemakai sistem ICT suatu organisasi yang tidak bergantung pada desktop. Sistem komputasi departemen (departmental computing systems) pada area berikutnya, mencakup penggunaan server, storage dan peralatan lainnya yang tidak berada di data center. Peralatan tersebut seringkali tidak efisien dalam 
penggunaan energi dan dalam penggunaan sumber daya, sehingga dijadikan sebagai target utama dalam penurunan energi. Area terakhir dalam tahapan ini adalah printing dan consumables. Pencetakan (printing) merupakan salah satu konsumsi utama dalam sumber daya di ICT. Sebuah alat printer, membutuhkan kertas serta toner atau tinta. Hal ini dapat menjadi masalah karena proses pencetakan serta pembuangan dari kertas bekas, toner, serta alat printer tersebut sangatlah susah untuk di daur ulang dan mengandung racun yang berbahaya.

Komponen vertikal ketiga adalah enterprise \& data center. Komponen ini terbagi menjadi lima bagian, yaitu data center ICT equipment, data center environmentals, networking \& communication, outsourcing \& cloud serta software \& architecture. Pada peralatan pusat data ICT (data center ICT equipment), memfokuskan pada dua tipe peralatan yang sangat penting yaitu server dan storage. Server merupakan pengguna daya terbesar sedangkan storage sendiri bertambah secara eksponensial dan diiringi dengan penurunan harga storage, penggunaannya sering tidak efisien. Dalam area data center environmental, memfokuskan pada tiga aspek utama, yaitu power supply, cool \& lighting serta bangunan tempat data center. Pada area networking \& komunikasi, terdapat beberapa hal yang berkaitan dengan komunikasi, di antaranya local area networking, wide area networking dan wireless communication.

Area keempat adalah outsourcing \& cloud, di mana outsourcing merupakan salah satu permasalahan besar pada dunia ICT. Isu ini berkembang seiring dengan perkembangan teknologi. Suatu organisasi haruslah mempertimbangkan tingkat efektifitas dari keputusan ini. Area terakhir yaitu, software architecture. Arsitektur software ini menentukan arsitektur dari hardware, yang menentukan secara signifikan pada jumlah dan tipe dari hardware yang digunakan.

Pilar yang terakhir adalah ICT sebagai low-carbon enabler. Di awal telah dibahas bahwa peralatan ICT menyumbang emisi karbon yang sangat besar. Terdapat lima area yang difokuskan yaitu, governance \& compliance, teleworking \& collaboration, business process management, business applications dan carbon emission management. ICT governance mengacu pada praktik dan metodologi yang menjamin bahwa ICT dikelola sebacara baik. Sedangkan corporate governance mengacu pada praktik dan metodologi yang memastikan bahwa korporasi dikelola secara baik. Teleworking mencakup berbagai teknologi dan praktik yang berkaitan dengan melakukan pekerjaan dalam jarak jauh dengan menggunakan berbagai macam teknologi seperti, teleconference \& video conference.

Area ketiga, business process management (BPM) merupakan proses peningkatan cara suatu organisasi atau individu dalam melakukan sesuatu dan membuatnya menjadi makin efisien dengan langkah yang lebih sedikit namun berdampak lebih besar. Area selanjutnya yaitu aplikasi bisnis. Aplikasi bisnis seperti ERP, SCM, CRM jika dilakukan sekecil apapun penambahan maka akan berdampak secara signifikan. Setiap organisasi memiliki proses yang unik yang dapat diefisienkan melalui penggunaaan aplikasi ICT tersebut. Carbon emissions management sebagai area yang terakhir dalam pilar ini memfokuskan pada pengelolaan dan pengurangan emosi karbon dalam suatu organisasi. Di dalamnya termasuk penggunaan sistem ICT yang dirancang secara spesifik untuk mengurangi carbon footprint.

Dimensi horisontal atau "tindakan (action)" pada kerangka kerja ini, dibagi menjadi lima komponen, yaitu attitude, policy, practice, technology dan metric (Gambar 4). Memiliki perilaku yang positif terhadap green ICT merupakan hal yang sangat penting. Perilaku (attitude) ini akan lebih efektif jika berasal dari para top management. Dari segi kebijakan (policy), suatu kebijakan pengurangan energi ICT harus holistik, koheren dan dikelola dan dipantau secara baik. Kerangka kerja pengembangan kebijakan meliputi pembuatan kebijakan, komunikasi dari kebijakan tersebut, pelaksanaan dari kebijakan dan pengukuran tingkat keefektifan dari kebijakan tersebut dan strategi mitigasinya. Praktik (practice) mengacu pada teknik dan perilaku pada saat kita melakukan sesuatu. Terdapat berbagai macam praktik yang dapat diadopsi oleh para individu dan organisasi yang dapat 
membantu menghijaukan fungsi ICTnya. Dan manfaat yang didapatkan adalah, praktik tersebut bisa didapatkan secara cuma-cuma tidak berkaitan dengan pembelian hardware ataupun software, tetapi cenderung kearah perubahan kebiasaan dan mindset. Misalnya seperti mematikan komputer pada saat tidak digunakan dan mendaur ulang kertas hasil print. Terkait dengan mindset, pernyataan ini diperkuat oleh hasil penelitian dari Chakraborty et.al. (2009), bahwa komputasi hijau merupakan sebuah mindset yang mempertanyakan bagaimana cara memuaskan peningkatan permintaan di bidang komputasi jaringan (computer network) tanpa memberikan banyak tekanan pada lingkungan tempat kita tinggal.

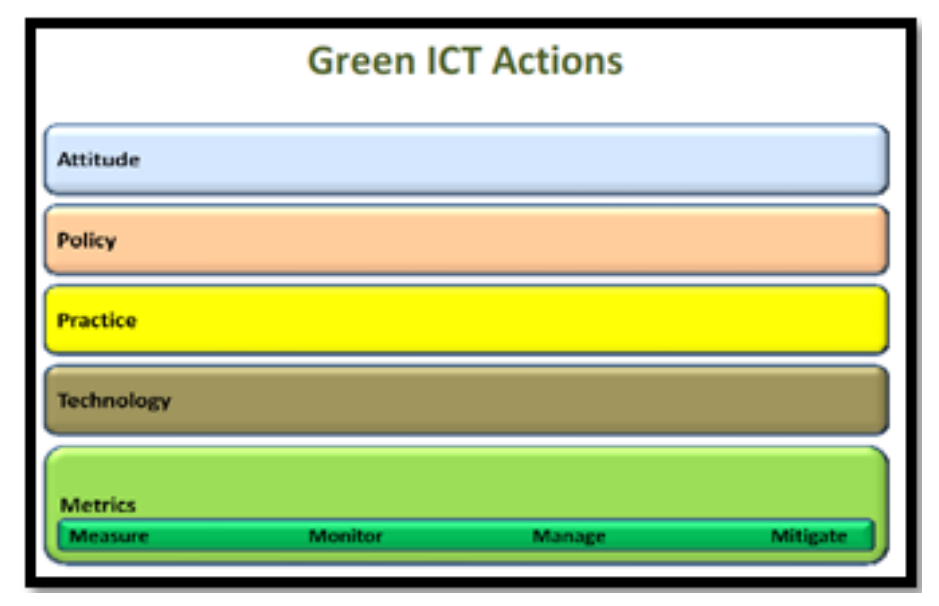

Gambar 4 Green ICT actions (Connection Research, 2010)

Tindakan yang berikutnya adalah berkaitan dengan teknologi. Biaya pembelian teknologi baru yang dianggap lebih "hijau" biasanya tidak sebanding dengan timbal baliknya. Pembuangan peralatan lama yang sebetulnya masih bisa digunakan, merupakan suatu pemborosan yang berakibat pada penambahan limbah elektronik. Cara paling baik adalah, menggunakan prinsip green ICT kedalam siklus penggantian peralatan. Tindakan yang terakhir yang harus diaplikasikan kepada keempat pilar tersebut adalah metric. Suatu strategi green ict haruslah mengidentifikasi secara jelas pengukuran pengurangan seperti, perolehan penghematan energi, pengurangan emisi karbon dan peningkatan daur ulang. Memilih tools yang tepat untuk mengukur, mengawasi, mengelola dan mengurangi konsumsi daya dan emisi karbon di dalam dan luar departemen ICT, sangatlah kritikal bagi kelangsungan proyek green ICT. Connection Research membagi menjadi empat proses metrik yaitu, measure, monitor, manage dan mitigate.

Langkah berikutnya adalah mengaplikasikan metrik pada masing-masing aspek di kerangka kerja tersebut untuk mengukur kemampuan level organisasi pada tiap aspeknya. Connection Research melakukannya dengan memodifikasi Cability Maturity Model (CMM) (Gambar 5). Connection Research menentukan level maturity melalui survei. Pertanyaan yang ditanyakan memfokuskan pada tindakan (actions) pada masing-masing pilar. Setiap pertanyaan diberikan skala dari 0 sampai dengan 5, kemudian setiap pertanyaan yang relevan pada masing-masing pilar tersebut di agregrasi dan diberikan bobot sehingga dapat menghasilkan nilai $(0-100)$. 


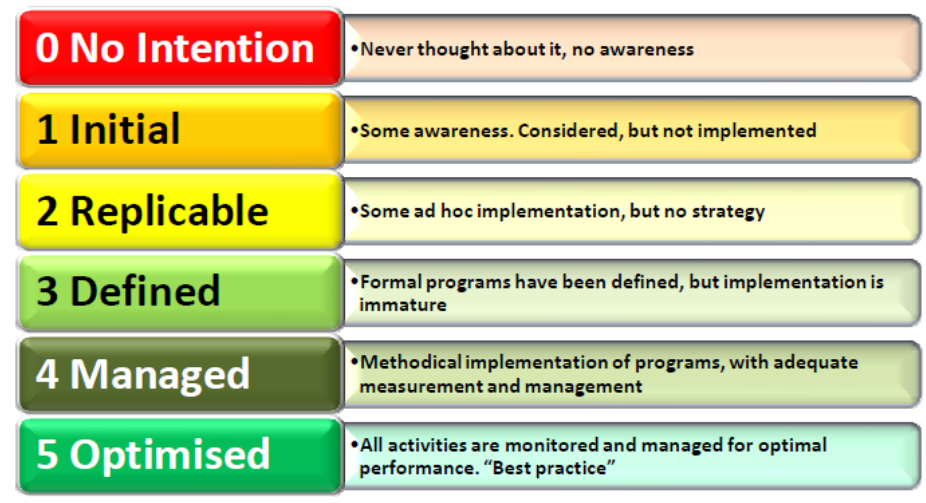

Gambar 5 Green ICT CMM

\section{Penerapan Green ICT Framework di Universitas Bina Nusantara}

Obyek penelitian model tata kelola komputasi hijau ini adalah Universitas Bina Nusantara. Pimpinan Universitas telah menetapkan visinya sebagai institusi pengetahuan yang berkelas dunia yang selalu mengedepankan inovasi dan pengembangan institusi. Karena visi tersebut, kampus menggunakan sistem dan teknologi informasi yang memadai dalam jumlah yang cukup besar, yaitu lebih dari 1500 buah PC dan ratusan notebook yang diutamakan untuk kebutuhan mobile computing. Secara garis besar data tentang lingkungan komputasi di Universitas Bina Nusantara berdasarkan keempat pilar dari model Green ICT milik RMIT-Connection Research dapat di lihat pada Tabel 1 - 4.

Tabel 1Kondisi Tata Kelola Peralatan di Universitas Bina Nusantara

\begin{tabular}{|c|c|c|}
\hline Pilar & Area & Kondisi di Universitas Bina Nusantara \\
\hline \multirow{8}{*}{$\begin{array}{l}\text { Tata Kelola } \\
\text { Peralatan }\end{array}$} & \multirow{4}{*}{$\begin{array}{l}\text { Tata Kelola } \\
\text { Pengadaan }\end{array}$} & PC Baru untuk SLC (Software Laboratories Center) \& Dosen di \\
\hline & & Kelas. \\
\hline & & Peremajaan 500 PC per tahun. \\
\hline & & Tingkat teknologi sesuai kebutuhan per tahun atau per semester. \\
\hline & \multirow{2}{*}{$\begin{array}{l}\text { Tata Kelola Daur } \\
\text { Ulang }\end{array}$} & Komputer staf merupakan komputer bekas dari SLC \\
\hline & & $\begin{array}{l}P C \text { yang sudah tidak digunakan oleh staff dijual/lelang/ } \\
\text { disumbangkan. }\end{array}$ \\
\hline & \multirow[t]{2}{*}{ Tata Kelola Limbah } & $\begin{array}{l}P C \text { yang sudah tidak digunakan akan dikumpulkan untuk } \\
\text { dijual/lelang atau disumbangkan. }\end{array}$ \\
\hline & & $\begin{array}{l}P C \text { yang akan dimusnahkan diajukan ke Procurement/Finance, } \\
\text { dengan syarat teknologi minimal lima tahun terakhir }\end{array}$ \\
\hline
\end{tabular}

Tabel 2Kondisi Tata Kelola End User Computing di Universitas Bina Nusantara

\begin{tabular}{|c|c|c|}
\hline Pilar & Area & Kondisi di Universitas Bina Nusantara \\
\hline \multirow[t]{5}{*}{$\begin{array}{l}\text { Tata Kelola End } \\
\text { User Computing }\end{array}$} & \multirow[t]{3}{*}{ Komputasi Desktop } & $\begin{array}{l}P C \text { digunakan oleh staff untuk kepentingan kerja \& } P C \text { diinstall } \\
\text { aplikasi pendukung untuk kegiatan pekerjaan. }\end{array}$ \\
\hline & & $P C$ yang digunakan merupakan $P C$ bekas SLC (setelah tiga tahun). \\
\hline & & Peremajaan dilakukan berdasarkan budget. \\
\hline & \multirow[t]{2}{*}{$\begin{array}{l}\text { Komputasi Mobile } \\
\text { Personal }\end{array}$} & $\begin{array}{l}\text { Notebook digunakan untuk para manager dan untuk kepentingan } \\
\text { mobile. }\end{array}$ \\
\hline & & $\begin{array}{l}\text { Notebook akan diremajakan jika sudah berumur tiga tahun } \\
\text { (maksimum lima tahun). }\end{array}$ \\
\hline
\end{tabular}




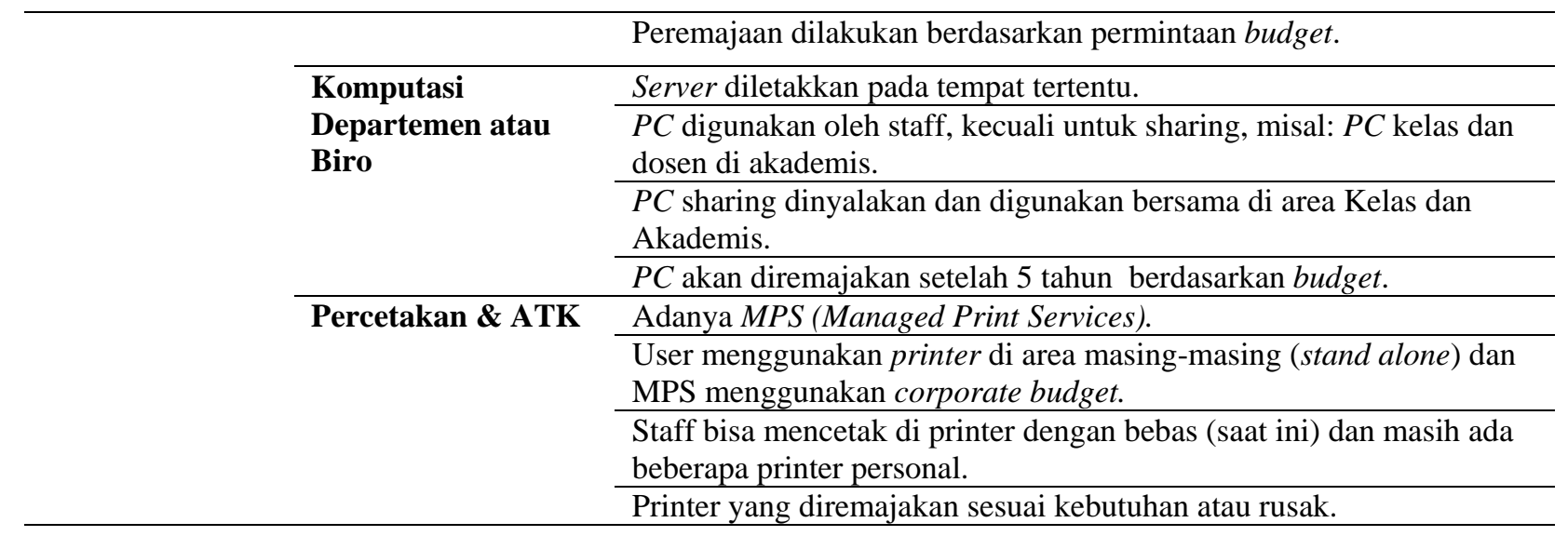

Tabel 3Kondisi Tata Kelola Pusat Data \& Universitas di Universitas Bina Nusantara

\begin{tabular}{|c|c|c|}
\hline Pilar & Area & Kondisi di Universitas Bina Nusantara \\
\hline \multirow{17}{*}{$\begin{array}{l}\text { Tata Kelola } \\
\text { Pusat Data \& } \\
\text { Universitas }\end{array}$} & \multirow{4}{*}{$\begin{array}{l}\text { Peralatan pada } \\
\text { Pusat Data SI/TI }\end{array}$} & Server rack digunakan untuk beberapa aplikasi, dan aplikasi \\
\hline & & Server dimonitor dengan aplikasi monitoring. \\
\hline & & $\begin{array}{l}\text { Teknologi server beragam, direncanakan untuk menggunakan } \\
\text { Blade/Virtualiasi. }\end{array}$ \\
\hline & & $\begin{array}{l}\text { Ukuran kontrol berdasarkan performa dari server, dan sumber } \\
\text { daya yang digunakan. }\end{array}$ \\
\hline & \multirow[t]{4}{*}{$\begin{array}{l}\text { Lingkungan Pusat } \\
\text { Data }\end{array}$} & $\begin{array}{l}\text { Menggunakan AC presisi, UPS dan Gen Set serta suhu udara } \\
\text { dikontrol dan monitor tidak lebih dari } 24 \text { d.c. }\end{array}$ \\
\hline & & Listrik dijaga agar tidak lebih dari 90\% utilisasi UPS. \\
\hline & & $\begin{array}{l}\text { Teknologi menggunakan AC Presisi dan UPS untuk Data center } \\
\text { dan Network Room. }\end{array}$ \\
\hline & & $\begin{array}{l}\text { Ukuran yang digunakan: suhu ruangan, utiliasi penggunaan } \\
\text { listrik di UPS. }\end{array}$ \\
\hline & \multirow[t]{4}{*}{$\begin{array}{l}\text { Jaringan Komputer } \\
\text { \& Komunikasi }\end{array}$} & $\begin{array}{l}\text { Router dan Main Switch terpusat di mana Main Switch } \\
\text { menggunakan Cisco Switch, Router internet menggunakan server } \\
\text { rack dan open source application. }\end{array}$ \\
\hline & & Monitoring dilakukan dengan aplikasi monitoring. \\
\hline & & Device networking masih menggunakan brand yang beragam. \\
\hline & & $\begin{array}{l}\text { Ukuran yang digunakan adalah: suhu ruangan (network room), } \\
\text { dan penggunaan listrik di UPS. }\end{array}$ \\
\hline & \multirow[t]{3}{*}{$\begin{array}{l}\text { Lingkungan Pusat } \\
\text { Data }\end{array}$} & $\begin{array}{l}\text { Belum menggunakan outsourcing maupun Cloud namun ada } \\
\text { rencana untuk menggunakan Google Apps dan Microsoft Live } \\
\text { Edu. }\end{array}$ \\
\hline & & $\begin{array}{l}\text { Untuk aplikasi yang tidak terlalu kritikal direncanakan akan } \\
\text { gunakan cloud. }\end{array}$ \\
\hline & & $\begin{array}{l}\text { Belum dilakukan praktek, jenis teknologi maupun cara } \\
\text { pengukurannya. }\end{array}$ \\
\hline & \multirow[t]{2}{*}{$\begin{array}{l}\text { Arsitektur } \\
\text { Perangkat Lunak }\end{array}$} & $\begin{array}{l}\text { Menggunakan Microsoft dan Linux Environment, di mana } \\
\text { aplikasi masih self-developed dan aplikasi dibuat berdasarkan } \\
\text { kebutuhan user. }\end{array}$ \\
\hline & & $\begin{array}{l}\text { Teknologi yang digunakan pada software aplikasi dikembangkan } \\
\text { oleh team IT sesuai kemampuan yang ada dan ada rencana } \\
\text { menggunakan CMMI framework. }\end{array}$ \\
\hline
\end{tabular}

Tabel 4Kondisi Tata Kelola SI/TI sebagai Penghasil Rendah Karbon di Universitas Bina Nusantara 


\begin{tabular}{|c|c|c|}
\hline Pilar & Area & Kondisi di Universitas Bina Nusantara \\
\hline \multirow{8}{*}{$\begin{array}{l}\text { Tata Kelola } \\
\text { SI/TI sebagai } \\
\text { Penghasil } \\
\text { Rendah Karbon }\end{array}$} & \multirow[t]{3}{*}{$\begin{array}{l}\text { Pengendalian dan } \\
\text { Ketaatan }\end{array}$} & $\begin{array}{l}P C \text { yang tidak digunakan dimatikan namun masih belum ada } \\
\text { governance yang baku dan juga masih belum ada prosedur yang } \\
\text { baku. }\end{array}$ \\
\hline & & $\begin{array}{l}\text { Teknologi yang ada pada } P C \text {, hardware dan software digunakan } \\
\text { berdasarkan jumlah yang berlaku. }\end{array}$ \\
\hline & & Disamping itu masih belum ada pengukuran yang baku. \\
\hline & \multirow{2}{*}{$\begin{array}{l}\text { Teleworking \& } \\
\text { Kerjasama }\end{array}$} & Mayoritas user bekerja di lokasi kerja masing-masing/di kampus. \\
\hline & & $\begin{array}{l}\text { Selain itu belum diterapkan, kecuali untuk email saja, begitu juga } \\
\text { cara pengukurannya. }\end{array}$ \\
\hline & \multirow[t]{3}{*}{$\begin{array}{l}\text { Manajemen Proses } \\
\text { Bisnis }\end{array}$} & $\begin{array}{l}\text { Kebijakan yang ada adalah diatur dengan prosedur ISO tetapi belum } \\
\text { ada monitoring utilisasi. }\end{array}$ \\
\hline & & $\begin{array}{l}\text { Menuju Sistem informasi yang saling terintegrasi, di mana } \\
\text { permintaan aplikasi menggunakan budget aplikasi. }\end{array}$ \\
\hline & & Belum ada pengukura untuk pengelolaan emisi karbon \\
\hline
\end{tabular}

\section{Model Tata Kelola Komputasi}

Berdasarkan data dan informasi yang diperoleh, dibentuk pola pikir sehingga terbentuklah sebuah model tata kelola yang ideal bagi perguruan tinggi. Dasar pemikiran yang dipakai adalah metodologi komputasi hijau oleh Adcuent (2010), di mana organisasi yang belum menerapkan komputasi hijau secara bertahap dan berkesinambungan akan berubah menjadi 'hijau'. Namun proses yang dilakukan menggunakan The Connection Research-RMIT Green ICT Framework, dengan beberapa perubahan yang diperlukan. Hasil pemodelan tata kelola komputasi hijau dapat dilihat pada matriks di Gambar 6.

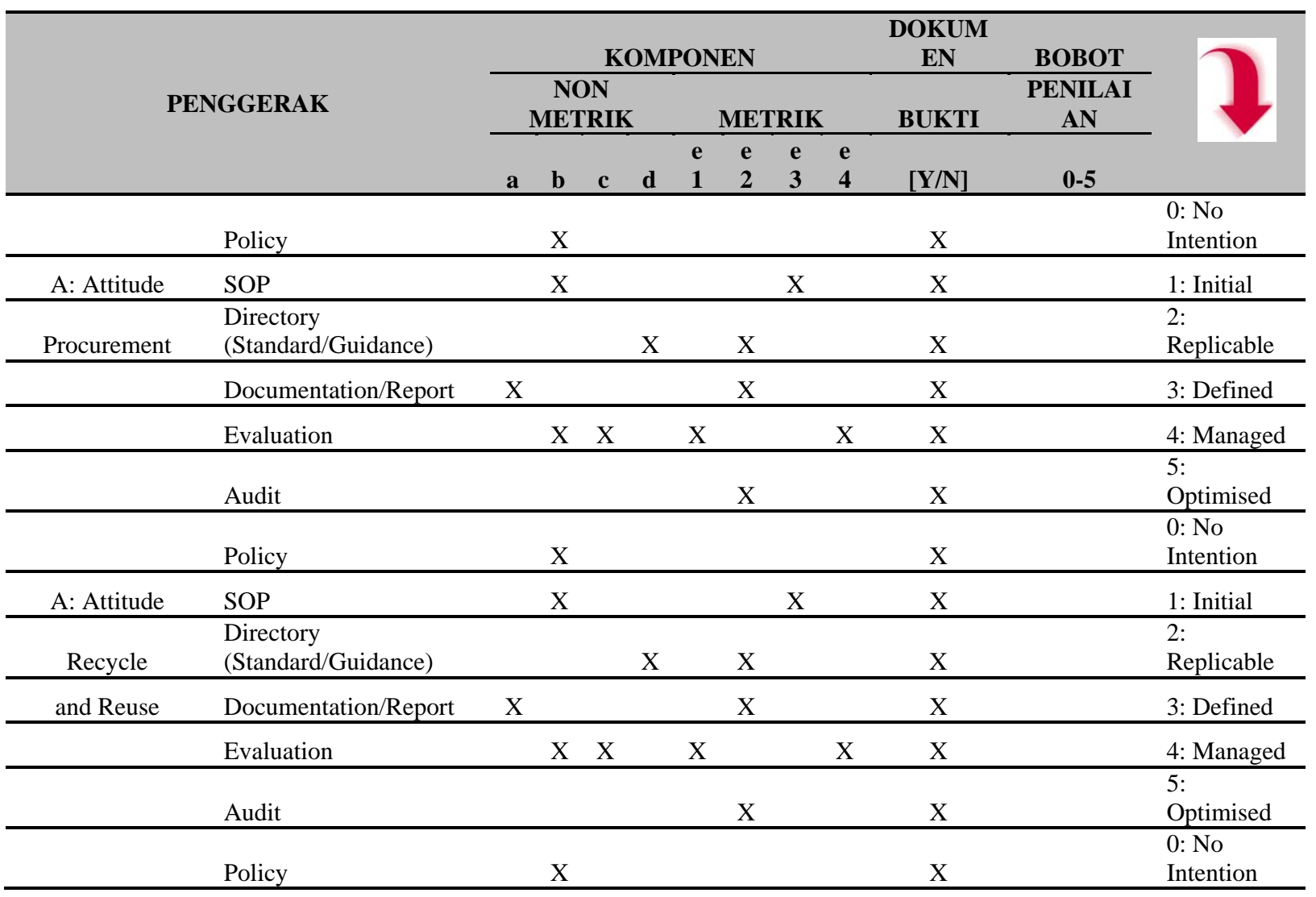




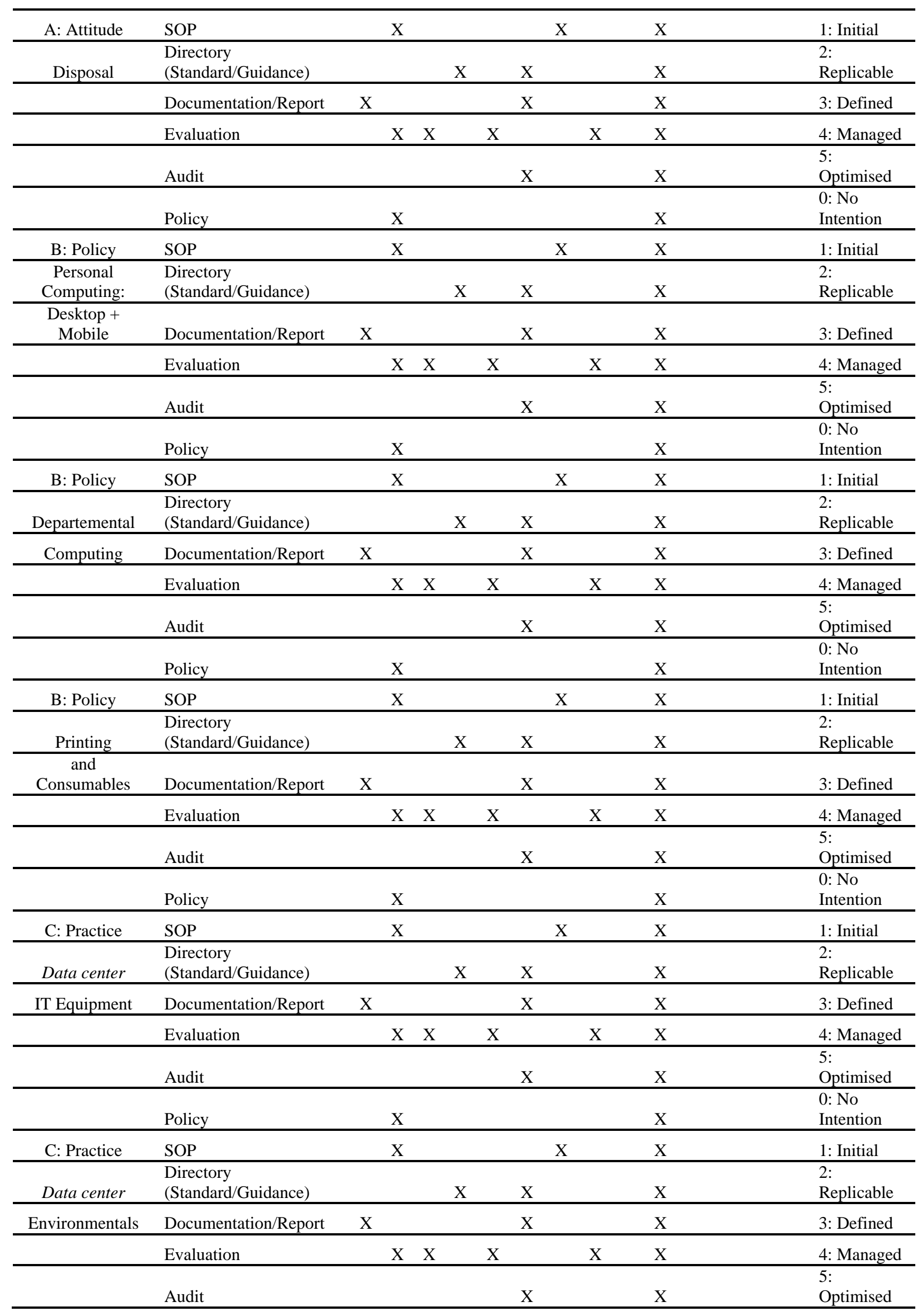




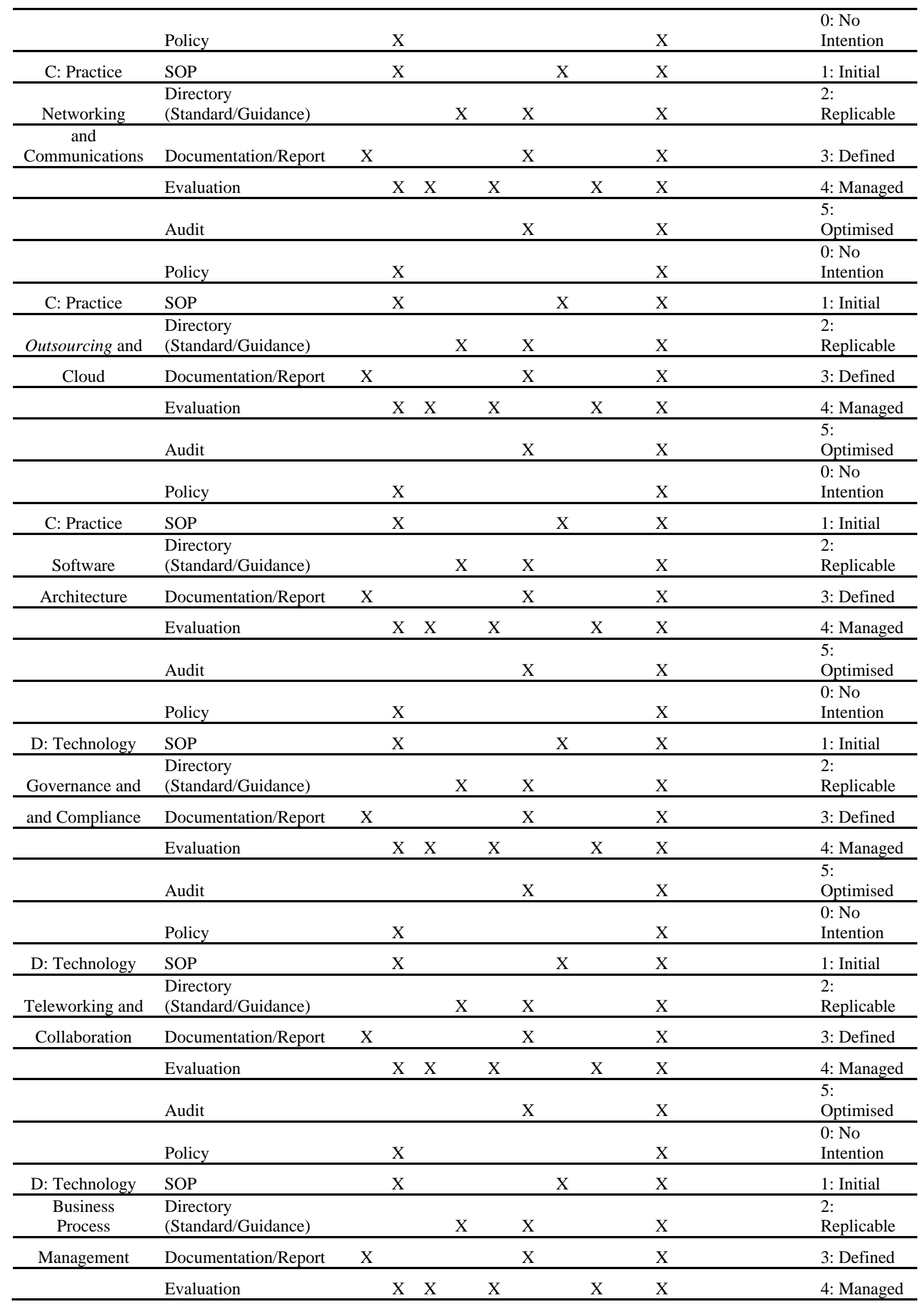




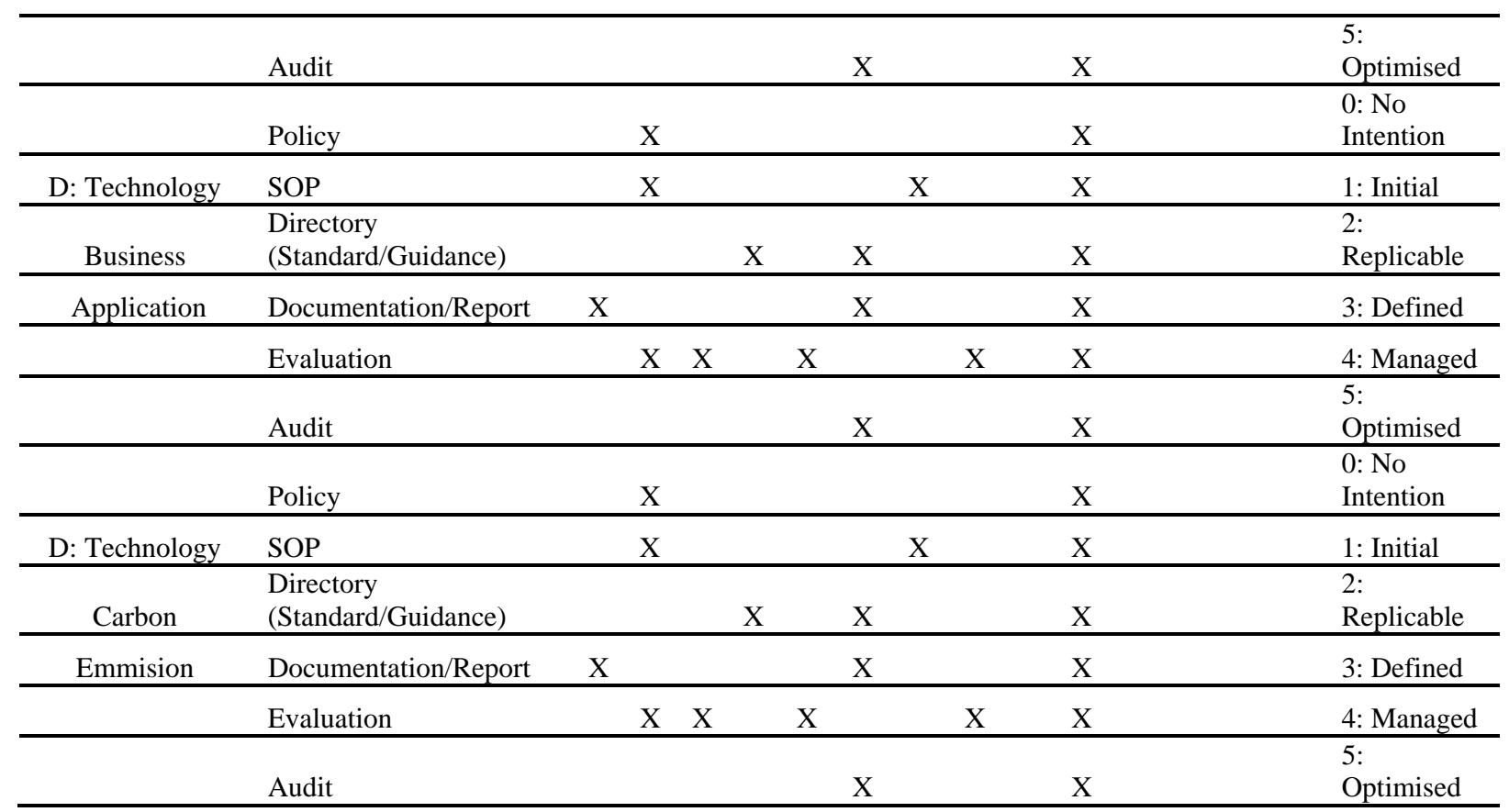

\section{Keterangan:}

$e$ adalah metric di mana e1: measure; e2: monitor; e3: manage; e4: mitigate

Gambar 6 Matriks komputasi hijau

\section{PENUTUP}

Model yang diusulkan, meskipun sudah dikaji dan dipikirkan matang, masih dirasakan beberapa kekurangan, di antaranya masih sulitnya penyederhanaan angket yang harus diisi yang sekaligus akan memudahkan perhitungan. Hasil perhitungan akan diklasifikasikan ke dalam enam kategori yang masing-masing diberi warna tertentu. Para pimpinan akan mudah memantau pada aspek apa saja yang masih menjadi kekurangan dan sekaligus mendapatkan jalan mengenai upaya apa yang mesti dilakukan agar kinerja tata kelola komputasi hijau ini meningkat. Secara keseluruhan usulan matriks ini akan berupa dokumen panduan sehingga akan mudah digunakannya. Penelitian ini masih perlu dikaji lebih lanjut agar menghasilkan luaran yang lebih baik.

\section{DAFTAR PUSTAKA}

Adcuent, I. (2010). Method-G ${ }^{\mathrm{TM}}$ : Green Computing Methodology. Diakses dari http://www.gotoyoursite.com/MethodG/tabid/4024/Default.aspx.

Barrett, P. M. (2012,). It's Global Warming, Stupid. Diakses November 30, 2012, dari http://www.businessweek.com/articles/2012-11-01/its-global-warming-stupid.

Chakraborty, P., Bhattacharyyal, D., \& Nargiza, S. (2009). Green Computing: practice of efficient and eco-friendly computing resources. International Journal of Grid and Distributed Computing, 2. 
Connection Research. (2010). A Green ICT Framework. Diakses dari http://www.computersite.com.au/assets/files/A_Green_ICT_Framework_CR.pdf.

Harris, J. (2008). Green Computing and Green IT Best Practices: on Regulations and Industry Initiatives, Virtualization, Power Management, Materials Recycling and Telecommuting. Queensland: Emereo Publishing.

Kochhar, N., \& Garg, A. (2011). Eco-Friendly Computing: Green Computing. International Journal of Computing and Business Research, 2 (2).

Lamb, J. (2009). The Greening of IT: How companies Can Make a Differences for the Environment. Boston: Pearson Education.

Sheikh, R. A., \& Lanjewar, U. A. (2010). Green computing-embrace a secure future. International Journal of Computer Application , 10 (4).

Stuenkel, M. (2009). Green IT Best Practices at the University of Michigan. Diakses September 4, 2012, dari http://www.educause.edu/ero/article/green-it-best-practices-university-michigan.

Talebi, M., \& Way, T. (2009). Methods, Metrics and motivation for a green computer science program. Proceeding of the 40th PACM Technical Symposium on Computer Science Education, Chattanooga.

Tomlinson, B. (2010). Greening through IT: Information Technology for Environmental Sustainability. Massachusetts: MIT Press.

University of Michigan. (2012). Sustainable Computing. Diakses December 2, 2012, dari http://sustainablecomputing.umich.edu/.

Utomo, Y. W. (2012, Oktober 31). Refleksi Al Gore tentang Badai Sandy. Diakses Januari 2013, dari http://sains.kompas.com/read/2012/10/31/12240049/Refleksi.Al.Gore.tentang.Badai.Sandy?ut m_source=WP\&utm_medium=Ktpidx\&utm_campaign=

Ward, J. L., \& Peppard, J. (2002). Strategic Planning for Information System (3rd ed.). West Sussex: John Willey. 